\title{
Development of human capital management system in the transportation industry
}

\author{
Elena Torosyan ${ }^{1}$, Olga Tcukanova $^{1, *}$, Karine Smesova ${ }^{1}$, Tatiana Feiling ${ }^{2}$, \\ and Olga Kalinina ${ }^{3}$ \\ ${ }^{1}$ ITMO University, Kronverksky pr., 49, 197101, St. Petersburg, Russia \\ ${ }^{2}$ FGBOU VO "RSHU" Federal State Budgetary Educational Institution of Higher Education "Russian \\ State Hydrometeorological University", Voronezhskaya St., 79, 192007, St. Petersburg, Russia \\ ${ }^{3}$ Peter the Great St. Petersburg Polytechnic University, Polytechnicheskaya st. 29, 195251, \\ St.Petersburg, Russia
}

\begin{abstract}
This paper discusses the importance and methods of Human Resource management in the high-technology companies of the Travel, Transport and Logistic industry. The qualification and motivation of the employees is a key factor of increasing the effectiveness and competitiveness of the big marker players. In this study the particular attention is paid to the digital tools and software to optimize and improve the quality of the HR business processes. As a result of this study, it was found that information technologies can reduce the time of the recruiting and hiring processing and present the detailed analytics on the workforce to the executive management. It would be interesting to consider the impact of investments in HR business process optimization on the general effectiveness of the transportation industry.
\end{abstract}

\section{Introduction}

The Travel, Transport and Logistic (TTL) industry (further - the industry) affects almost to the each sector of the global economic. Every day the goods and services are delivered to the customers and people from all over the world are using public and private transport.

On the other hand, IT companies support the TTL industry by devising improvement programs to eliminate competitive their disadvantages and seek out new solutions for ailing sections of transportation networks. Digital technologies are the key driver of recent changes in the TTL and will be so in the future, although today's pace of technological development and adoption can make that future hard to predict.

Leading companies want to attract and retain the top talent employees from around the world to ensure that their businesses continue to grow and prosper and are able to adapt swiftly to change. As getting the right people is so crucial to ongoing commercial success, human resources (HR) is considered as a key business function [1-3].

The term "Talent management" was coined by Steven Hankin of McKinsey\&Company in 1997. The consultants of the MsKinsey\&Company have investigated the case in the big companies when the talented employees were leaving the big companies (e.g. Procter \&

\footnotetext{
${ }^{*}$ Corresponding author: zoa1999@mail.ru
} 
Gamble and General Electric and 77 other companies) preferring the smaller ambitious business or start-ups [4-5].

Nowadays, this case is relevant to the each company, especially, in the high-technology industry, where the innovative ideas are intrinsically associated to the future success.

The ability to adapt, to make decisions quickly in situations of high uncertainty, and to steer through change is quite important when you are making a crucial decision as a manager. But at the same time, this decision is not going to work if your employees are not enough motivated to implement it or your values and goals are not clear understandable to them. It is possible to claim, that all employees should participate in the establishment and implementation of company's strategy. Employees should work together as a team and thus ensure company's success and personal well-being. From the other side, company can work effectively only if the interests of the employees and employer are corresponded. When the employer is interested in the business grow, the employees are concentrated on their career development. Sometimes to achieve the balance between the interests of the parties becomes the start point of success.

In this study the following terms are considered:

- "Human Resources (HR) management" - the organization strategy of headcount management, including planning and budgeting, hiring and termination compensation and payroll,

- "Talent Management" (TM) - a part of HR management process, including methods and tools for staff recruiting and retaining employees in the company (e.g. staff motivation, development and learning, performance management);

- "Talent Management systems" (TMS) - software designed for the Talent management processes automatization.

Tools and methods described in the study can be integrated with the organization strategy as in transportation industry, as any high-tech companies [6-7]

\section{Materials and Methods}

There are many factors that influence to the candidates before he make a decision to apply for a position or to take a "job offer". Moreover, these factors can change depend of the social trend or the time: for example, if the one/two decades ago the candidates was focused on the salary, today candidate are more ambitions and career-grow oriented. The detailed career path from the average candidate view is shown on the figure 1.

On the other hand, the companies are interested in the employees development to achieve their business goals. The detailed career path from the company management view is shown on the figure 2 .

As we can see on the figures bellow, the stages of the career path are mostly similar for the both side (Candidate and Company). Each of the parties pursues its own interests, but at the same time, the tools and methods for achieving the result (successful career of an employee) should be uniform. Summarizing, the following components of Talent management process are applicable for the both side and can be considered for automatization:

- Staff recruiting and hiring,

- Staff onboarding (including Goals settings),

- Staff learning,

- Performance and development,

- Assessment and monitoring,

- HR analytics. 


\section{"Career Path" (Candidate view)}

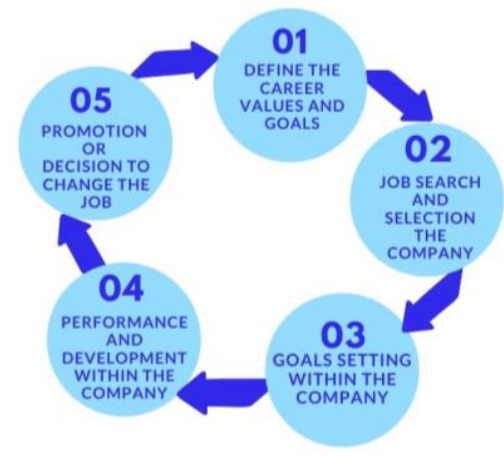

Fig. 1. "Career path" (Candidate view).

\section{Employee "Career Path" in the Company}

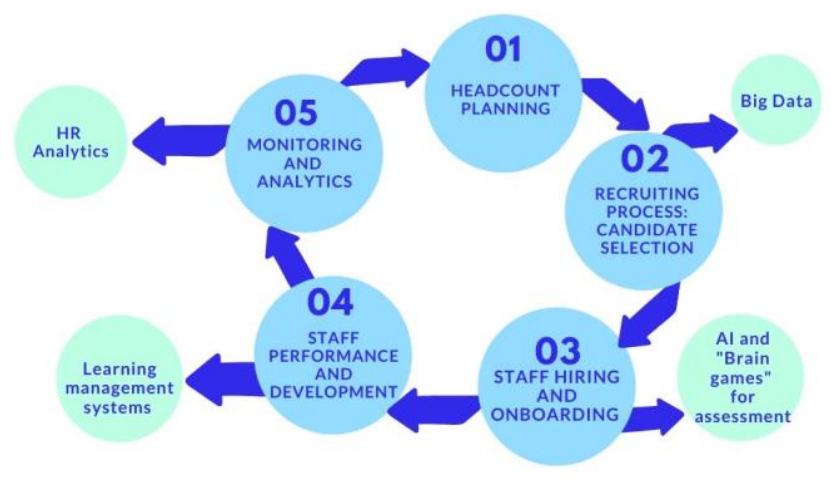

Fig. 2. Employees "Career path" in the Company.

\subsection{Staff recruiting and hiring}

Once the Company based on the Headcount planning data (please refer to figure 1) made a decision to hire new staff, the HR specialists should firstly define the most important characteristics and requirements to the candidate (e.g. education, work experience, hard and soft skills, etc.) that are relevant to the open position.

Then, the HR specialist starts the recruiting process by searching the candidates with the relevant skills via the Internet recourses (e.g. Headhunter, LinkedIn and other) and organizing assessment for the most potential ones.

The following methods of candidate assessment can be considered:

- CV (Curriculum Vitae) and CL (Cover Letter) screening,

- Interview / Video-interview,

- Test (e.g. Problem-solving tests, Logic and Verbal tests, etc.),

- Case-interview,

- other.

The assessment information should be analyzed to define the most successful candidate. The potential risks and opportunities for optimization are shown in the table 1. 
Table 3. Risks and opportunities of Staff recruiting and hiring process.

\begin{tabular}{|l|l|l|}
\hline Sub-process name & Risks & Opportunities \\
\hline Candidates search & 1 Big data analyzing, & 1 Usage information \\
& 2 Unstructured data, & technologies for data \\
& 3 Data loss (including & processing, analyzing and \\
& personal data loss), & 2 Usage Robotic Process \\
& & Automation (RPA) for \\
& & routine tasks \\
\hline Candidates assessment & Candidates assessment is & Usage Assessment Tools and \\
& not independent & Artificial Intelligence (AI) \\
\hline
\end{tabular}

"Pymerics" is an example of Assessment Tool - career search platform that can be installed on the Mobile phone or PC. The developers of the tool used the neuroscience and machine learning. Within the recruiting process, the candidates can be examined via this application.

The following steps of assessments are included:

1. "brain games" - the user plays the logic games (currently, there are 12 mandatory and 8 additional games),

2. the algorithm analyses the user answers and presents the results: information on the candidate skills and potential job for him.

\subsection{Staff Onboarding and Learning}

The employee Onboarding is a long-term process that introduces the employee to what the employee will be responsible for accomplishing in the first 30/60/90 days to one year on the job. New joiners are given the goals and expectations of their role, in addition to specific training for their new position. They will have to get to know the company's history and its business strategy, as well as understanding how that relates to their own role and its objectives.

Then, based on the company global business goals the employee and his Line manager determine personal goals related to the employee career expectation within the company. As a result, the individual Development plan should be prepared.

Individual Development plan is intrinsically associated to the corporate learning process. The learning process might include mandatory (e.g. Independence, Compliance and others) and non-mandatory trainings. Depends on the company specifics the staff learning process might be organized on the different ways. In purpose to develop the process, the following position should be determined:

- types of the trainings (online trainings/local or external classrooms/etc.) that can be requested by the employees of certain grades and functionality;

- Individual learning plan and employees trainings requests approval workflow;

- relation of the training request to the Development plan;

- Individual learning plan processing for budgeting purpose.

Learning management systems (LMS) is a software application or web-based technology used to plan, implement and assess a specific learning process. It is used for elearning practices and, in its most common form, consists of two elements: a server that performs the base functionality and a user interface that is operated by instructors, students and administrators. LMS might be integrates with the internal software or used as a separated tool. 


\subsection{Staff Performance and Development}

Depends on the company specifics the staff Performance and Development processes might be organized on the different ways.

In general, Performance management includes annual based results employee evaluation processes. The results of Performance management the annual employee assessment and the final annual bonus.

Employee Development process includes the processes of grade and position change based on the results of Talent review (or employee Assessment process).

Usually, the employee Assessment process might use one o the following methods:

- $\quad$ interview with the Line manager,

- tests,

- $\quad$ assessment center (including games, cases and team work),

- other.

However, according to the Harvard Business Review research, big high-technology companies (e.g. Adobe, Juniper Systems, Dell, Microsoft and IBM) and consulting companies (e.g. PwC, Deloitte, and Accenture) refuse such assessment methods due this process take a lot of time and finance, but not always shows actual picture. Instead of it, they pay additional attention to the recruiting processes and employee motivation and development [8].

\subsection{HR analytics}

HR analytics is a methodology for creating insights on how investments in human capital assets contribute to the success of four principal outcomes

- $\quad$ generating revenue,

- minimizing expenses,

- $\quad$ mitigating risks,

- $\quad$ executing strategic plans.

This is done by applying statistical methods to integrated HR, talent management, financial, and operational data.

Types of analytics: HR Analytics, People Analytics, and Workforce Analytics

HR analytics: HR analytics specifically deals with the metrics of the HR function, such as time to hire, training expense per employee, and time until promotion. All these metrics are managed exclusively by HR for HR.

People analytics: People analytics, though comfortably used as a synonym for HR analytics, is technically applicable to "people" in general. It can encompass any group of individuals even outside the organization. For instance, the term "people analytics" may be applied to analytics about the customers of an organization and not necessarily only employees.

Workforce analytics: Workforce analytics is an all-encompassing term referring specifically to employees of an organization. It includes on-site employees, remote employees, gig workers, freelancers, consultants, and any other individuals working in various capacities in an organization.

Here are some common metrics tracked by HR analytics:

1. Revenue per employee: Obtained by dividing a company's revenue by the total number of employees in the company. This indicates the average revenue each employee generates. It is a measure of how efficient an organization is at enabling revenue generation through employees.

2. Training expenses per employee: Obtained by dividing the total training expense by the total number of employees who received training. The value of this expense can be 
determined from measuring the training efficiency. Poor efficiency may lead you to reevaluate the training expense per employee.

3. Training efficiency: Obtained from the analysis of multiple data points, such as performance improvement, test scores, and upward transition in employees' roles in the organization after training. Measuring training efficiency can be crucial to evaluate the effectiveness of a training program.

4. Time to fill: The number of days between advertising a job opening and hiring someone to fill that position. By measuring the time to fill, recruiters can alter their recruitment strategy to identify areas where the most time is being spent.

5. Time to hire: The number of days between approaching a candidate and the candidate's acceptance of the job offer. Just like time to fill, data-driven analysis of time to hire can benefit recruiters and help them improve the candidate experience to reduce this time.

6. Human capital risk: This may include employee-related risks, such as the absence of a specific skill to fill a new type of job, the lack of qualified employees to fill leadership positions, the potential of an employee to leave the job based on several factors, such as relationship with managers, compensation, and absence of a clear succession plan. HR analytics can be used to measure all these metrics [9-10]

\section{Results and Discussion}

Discussing the modern methods and approaches that are used in the big companies, it was would be interesting to analyze the digital market to define the solutions that can optimize all HR business processes mentioned above. Within the research, the following software for was considered:

- $\quad$ SAP Success Factors,

- Oracle Taleo Business Edition,

- Workday.

The results of analyze is shown in the table 2 .

Table 2. HR management systems.

\begin{tabular}{|l|l|l|l|}
\hline & Success Factors & $\begin{array}{c}\text { Oracle Taleo } \\
\text { Business Edition }\end{array}$ & Workday \\
\hline Staff recruiting & + & + & + \\
\hline Onboarding & + & - & + \\
\hline Assessment & + & + & + \\
\hline Goals management & + & + & + \\
\hline Motivation & + & + & + \\
\hline Learning & + & - & + \\
\hline Headcount panning & + & - & + \\
\hline HR Analytics & + & - & + \\
\hline
\end{tabular}

As we can see from the table, all the systems enable to manage the HR business processes. However, according to the annual report "Digital HR 2019" prepared by the consulting company Deloitte, almost $55 \%$ of companies still use the paper-based and $60 \%$ of HR specialists manually prepare HR analytics. Only 3\% of companies use predictive analyses and machine learning and $7 \%$ of companies use AR/VR technologies.

This statistics shows that there is a huge potential to grow in the HR management, but the decision to change the approach for HR management is still on the executive managers side. 


\section{Conclusion}

1. The role of HR management determines organizations' performance results and its position in the market, i.e. it enables to achieve greater income and become more competitive in the market.

2. The successful "Career path" for the Candidate to the experiences employee is a huge work as for the individual, as for the company. To achieve the balance between the parties interests mean to improve the chances to become more innovative and to develop cutting-age technologies in the transportation industry.

3. Modern software in the HR management can provide the companies with the highquality analytics and reduce the time of routine task processing.

4. In accordance with the obtained results, it is possible to claim, that all employees should participate in the establishment and implementation of company's strategy. Employees should work together as a team and thus ensure company's success and personal well-being.

\section{References}

1. M. Grazia Speranza, European Journal of Operational Research 264, 830-836 (2018).

2. M. González-Loureiro, M. Dabic, F. Puig, International Journal of Physical Distribution \& Logistics Management 44(89), 689-712, (2014).

3. N. Batarlienè, K. Čižiūnienè, K. Vaičiūtè, I. Šapalaitė, A. Jarašūnienè, Transportation Science and Technology Procedia Engineering 187, 110 - 116, (2017)

4. D.G. Collings, H. Scullion, V. Vaiman, Human Resource Management Review, 25, 233-235, (2015).

5. T.N. Krishnan, H. Scullion, Human Resource Management Review 27, 431-441, (2017).

6. M.Černe, S.Batistič, R.Kenda, Human Resource Management Review 28, 271-288, (2018).

7. D.Daud, Trends in Human resources management practice: a perspective from practitioners in logistics organizations, Academic Research International 8, 9-16 (2017).

8. P. Cappely, A. Tavis, Harvard Business Review, (2019). URL:https://hbr.org/2016/10/the-performance-management-revolution]

9. N.A. Miranty, Advanced Science Letters 24, 5426-5430, (2018).

10. N.S. Nikitinsky, Scientific-Practical Conference "Research and Development - 2016", 73-82 (2016). 